\title{
Diffusion-Weighted Magnetic Resonance /maging in Diagnostics of Spinal Nerve Root Compression in Patients with Lumbar Intervertebral Disc Herniation
}

DOI: $10,17691 / \mathrm{stm} 2019.11 .3 .14$

Received June 18, 2018

1.A. Stepanov, PhD Student, Department of Neurosurgery and Innovative Medicine";

N.A. Tetyushkin, Clinical Resident, Department of Neurosurgery and Innovative Medicine';

M.A. Shameeva, Clinical Resident, Department of Neurosurgery and Innovative Medicine";

V.A. Byvaltsev, MD, DSc, Head of the Department of Neurosurgery and Innovative Medicine ${ }^{1 ;}$

Deputy Director of Innovative and International Affairs'; Professor, Department of Traumatology,

Orthopedics and Neurosurgery ${ }^{3}$; Chief of the Neurosurgery Center ${ }^{4}$

1rkutsk State Medical University, 1 Krasnogo Vosstaniya St., Irkutsk, 664003, Russia;

2 Irkutsk Scientific Center of Surgery and Traumatology, $1 \mathrm{G}$ Bortsov Revolutsii St., Irkutsk, 664003, Russia;

${ }^{3}$ Irkutsk State Medical Academy for Postgraduate Education - Branch of the Russian Medical Academy

of Continuing Professional Education of the Ministry Healthcare of the Russian Federation,

100 Yubileyny Microdistrict, Irkutsk, 664049, Russia;

${ }^{4}$ Railway Clinical Hospital at the Irkutsk-Passagirsky Station of RZD-Medicine, 10 Botkin St., Irkutsk,

664005, Russia

The aim of the study was to evaluate possibilities of using diffusion-weighted MRI (DW MRI) in diagnostics of compression of dorsal spinal ganglia and spinal nerve roots in patients with lumbar intervertebral disc herniation (IVD).

Materials and Methods. The study involved 37 patients (19 males, 18 females, average age $-42.6 \pm 12.7$ ) with radicular syndrome caused by an IVD hernia of the lumbosacral spine. In all the cases, the diagnosis was confirmed by a clinical-neurological examination of a patient, radiography of the lumbar spine, multi-layer spiral CT and MRI investigations (including DW MRI). The control group included 29 volunteers (16 males, 13 females, average age $-37.4 \pm 9.6$ ), who do not have clinical neurological and neuroimaging signs of a degenerative disease of lumbar IVD.

Results. Average value of the measured diffusion coefficient (MDC) compressed by the hernia of L5 IVD root amounted to $1634.7 \mathrm{~mm}^{2} / \mathrm{s}$, and the value of the intact - to $1109.2 \mathrm{~mm}^{2} / \mathrm{s}$. MDC for the right-sided S1 root without compression signs was $1392.5 \mathrm{~mm}^{2} / \mathrm{s}$, while for the left-sided one it was $1375.7 \mathrm{~mm}^{2} / \mathrm{s}$. The average MDC value for proximal regions of the spinal roots on the hernia side was $1441.2 \pm 13.7 \mathrm{~mm}^{2} / \mathrm{s}$, and for the roots on the intact side it was $1243.9 \pm 17.6 \mathrm{~mm}^{2} / \mathrm{s}(p<0.001)$. Average MDC values for the distal regions of the roots on the degenerated IVD side were $1446.8 \pm 173.4$ and $1107.5 \pm 76.1 \mathrm{~mm}^{2} / \mathrm{s}$, respectively $(p<0.001)$. There is an evident direct correlation between MDC of the dorsal spinal ganglion and pain intensity according to VAS $\left(r_{s}=0.089 ; p=0.012\right)$.

Conclusion. A specificity of compressed dorsal spinal ganglia and spinal nerve roots is their high MDC values which show microstructural changes manifested by edema, demyelination, and axonal injury. DW MRI, which enables the MDC to be calculated, is a perspective method of non-invasive instrumental diagnostics of compression nerve root syndromes in patients with degenerative IVD diseases.

Key words: diffusion-weighted MRI; measured diffusion coefficient; dorsal spinal ganglion; spinal nerve root; intervertebral disc hernia.

\section{Introduction}

Radicular pain in patients with sciatica was first described by a neurosurgeon from Harvard University, William Mixter, and his colleague, orthopedist Joseph Barr in 1934 [1]. The authors clearly demonstrated that compression of the spinal nerve root by a fragment of an intervertebral disc (IVD) was underlying this pain syndrome; however, pain pathophysiology in this condition has not been fully disclosed yet. Currently, more and more researchers are of the opinion that the key role in the development of a nerve root pain syndrome belongs to a dorsal spinal ganglion (DSG) [2, 3].

Diffusion-weighted magnetic resonance imaging (DW MRI) is a modern instrumental non-invasive method based on measurement of a diffusion degree of free water molecules in different tissues [4]. A quantitative measure of the diffusion degree of water molecules in tissue is the measured diffusion coefficient (MDC). Various MDC values represent a functional map of

Corresponding author: Vadim A. Byvaltsev, e-mail: vadimabyvaltsev@gmail.com 
diffusion-weighted images (DWI) [5]. Earlier we received successful results of using DW MRI for the diagnostics of a degree of the degenerative IVD disease and its postmortem changes [6-10]. There are works confirming that DW MRI method that measures MDC allows diagnosing various pathological states of the central and peripheral nervous systems like multiple sclerosis [11], carpal tunnel syndrome [12] and various demyelinating processes [13].

Neurovisualization of the spinal cord and its roots by DWI mapping is a complex technical task associated with small size of the spinal cord, presence of multiple artifacts from the surrounding tissues and artifacts related to respiratory movements of a patient [14]. However, Takahara et al. [15] proved in their research that visualization of the spinal cord, its roots and peripheral nerves with DW MRI is an acceptable method of diagnostics.

A search through reference sources in the up-to-date databases revealed that there is only one message devoted to the study of the DW MRI role in diagnostics of DSG and spinal nerve root compression in patients with lumbar IVD herniation. And the findings obtained by the authors were rather unclear [16].

The aim of this study was to evaluate possibilities of using diffusion-weighted MRI in diagnostics of compression of dorsal spinal ganglia and spinal nerve roots in patients with lumbar intervertebral disc herniation.

\section{Materials and Methods}

We carried out an open non-randomized cohort multicenter retrospective study from February 2017 to May 2018 in the Center of Neurosurgery of the Railway Clinical Hospital at the Irkutsk-Passagirsky Station of RZD-Medicine.

The study involved 37 patients ( 19 males, 18 females, average age - 42.6 \pm 12.7 ) with radicular syndrome caused by an IVD hernia of the lumbosacral spine. In all the cases the diagnosis was confirmed by a clinicalneurological examination of a patient, radiography of the lumbar spine, multi-layer spiral CT and MRI investigations (including DW MRI). The control group included 29 volunteers (16 males, 13 females, average age $-37.4 \pm 9.6$ ), who do not have clinical neurological and neuroimaging signs of a degenerative disease of lumbar IVD.

The inclusion criteria were the following: 1) presence of bi- or polyradicular clinical-neurological symptoms; 2) central stenosis of the spinal canal; 3) surgery on the lumbosacral spine in the medical history.

The clinical-neurological examination of a patient involved studying of their neurological status (presence of motor and sensory disorders), intensity analysis of the pain syndrome according to visual analogue scale (VAS) and analysis of patients' quality of life according to Oswestry Disability Index (ODI).
Radiography of the lumbar spine was performed with Digital Diagnost (Philips, the Netherlands), multi-layer spiral CT of the lumbosacral spine was carried out with Somatom Perspective 64 (Siemens, Germany).

Diffusion-weighted MRI with DWI mapping was carried out on Magnetom Essenza 1.5 T (Siemens, Germany). In the investigation in the mode of T1-weighed images (T1-WI) we used the following parameters: matrix $384 \times 387$; repetition time (TR) - $650 \mathrm{~ms}$; echo time (TE) - $9.6 \mathrm{~ms}$; number of excitation (NEX) - 1; slice thickness $-4 \mathrm{~mm}$; field of view (FOV) $-30 \times 30$; in T2-WI mode: matrix — 384×288; TR - $4000 \mathrm{~ms}$; TE $43 \mathrm{~ms}$; NEX - 1; slice thickness - $4 \mathrm{~mm}$; FOV $30 \times 30$.

To obtain DWI maps we used the following set of parameters for DW MRI option with SE-echo-planar image (EPI): matrix - 160×128; TR - $7500 \mathrm{~ms}$; TE $83 \mathrm{~ms}$; NEX - 6; slice thickness - $4 \mathrm{~mm}$; FOV $30 \times 30$. We used the values of b-coefficient equal to 400 and 800 ; the time of scanning was 6 min $30 \mathrm{~s}$.

The measured diffusion coefficient was calculated in T2-WI mode with RadiAnt DICOM Viewer. The obtained values were used for making functional DWI maps. The obtained T1-WI, T2-WI and DWI maps were used for measurement of morphometric DSG parameters (length and width) and calculation of MDC values in the group of patients with lumbar IVD herniation and in the group of volunteers without the signs of IVD degeneration.

The study protocol was approved by the Ethics Committee of Irkutsk State Medical University. The study complied with the principles of Good Clinical Practice and Helsinki Declaration [17]. Before the beginning of the study all the patients provided written informed consent.

The findings were statistically processed with Microsoft Excel 2010. DMC values in two groups under study were compared with a Mann-Whitney test. A correlation test between MDC values and clinical parameters (pain intensity according to VAS, life quality according to ODI) was carried out with Spearman's rank correlation $\left(r_{s}\right)$. The degree of correlation was measured in the following way: if the value was $r_{s}>0.7$ it was assessed as a significant correlation, at $0.5<r_{\mathrm{s}} \leq 0.7$ as a moderate and at $r_{s}<0,5$ as a weak one. Statistically relevant were the differences at $p<0.05$.

\section{Results}

When the group of healthy volunteers without any signs of the degenerative diseases of lumbar IVD was examined with DW MRI and their spinal nerve roots of the lower lumbar spine (from L4 to S1) were visualized for DWI mapping, the average values of DSG length at $\mathrm{L} 4$, L5, and S1 were 7.1 $\pm 1.3,9.5 \pm 1.7$, and $6.3 \pm 0.6 \mathrm{~mm}$, respectively, average length values were 5.1 \pm 0.7 , $6.3 \pm 0.6$, and $5.8 \pm 0.5 \mathrm{~mm}$, respectively. No reliable differences in length and width of the left-sided and rightsided DSG were identified. It is necessary to mention that DSG length increased from L4 level up to S1 level, 
and DSG width increased from L5 level and decreased to S1 level.

The average MDC values for L4, L5, and S1 DSG in healthy volunteers were $1124.6 \pm 117.3,1239.3 \pm 121.5$, and $1261.2 \pm 117.4 \mathrm{~mm}^{2} / \mathrm{s}$, respectively. Average MDC values for the given roots were 1121.8 \pm 98.5 , $1127.5 \pm 87.3$, and $1165.6 \pm 103.7 \mathrm{~mm}^{2} / \mathrm{s}$, respectively. There were no statistically relevant differences between MDC values of DSG and spinal nerve roots on the right and left sides. MCD of DSG and spinal nerve roots increased from L4 to S1 level.


Figure 1. In DW MRI-images of lumbosacral spine at $L_{V}-S_{1}$ level a leftsided foraminal IVD hernia with the compression of L5 spinal nerve root is visualized (shown with an arrow):

(a) T2-WI, sagittal slice; (b) T2-WI, frontal slice; (c) DWI map, frontal slice (MDC of the proximal region of L5 nerve root is $1241 \mathrm{~mm}^{2} / \mathrm{s}$ ); (d) T2-WI, axial slice; (e) DWI map, axial slice (MDC of the left DSG at the given level is $1439 \mathrm{~mm}^{2} / \mathrm{s}$ )
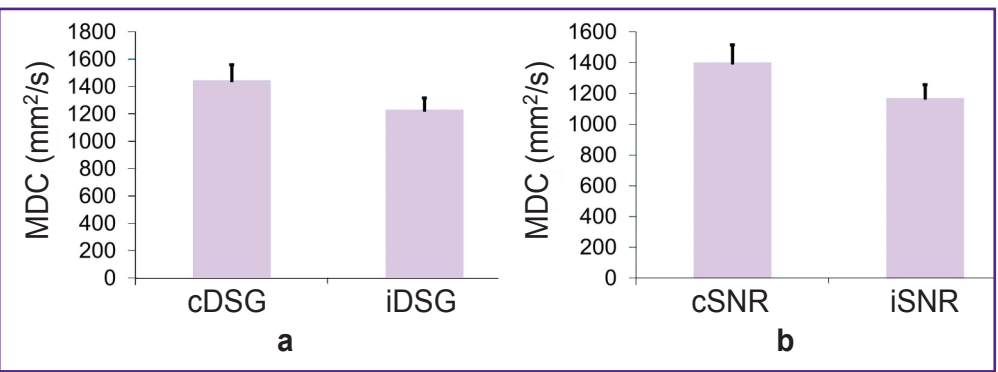

Figure 2. Comparison of average MDC values:

(a) dorsal spinal ganglia compressed with a hernia of an intervertebral disc (cDSG) and intact ones (iDSG) ( $p<0.01$ ); (b) spinal nerve roots, compressed (cSNR) and intact (iSNR) ones $(p<0.001)$
When DW MRI of the lumbosacral spine in different des in patients with IVD hernias was carried out, were registered the signs of compression and hernia spinal nerve root at L5 was $1634.7 \mathrm{~mm}^{2} / \mathrm{s}$, and of the intact nerve was $1109.2 \mathrm{~mm}^{2} / \mathrm{s}$ (Figure 1 (d), e)). At the same time the MDC value for the rightsided root at S1 without compression signs was $1392.5 \mathrm{~mm}^{2} / \mathrm{s}$ and for the left-sided one it was $1375.7 \mathrm{~mm}^{2} / \mathrm{s}$. No statistically relevant differences in the above-mentioned parameters were registered for the left-sided and right-sided spinal nerve roots.

The average MDC value for the proximal regions of the spinal nerve roots on the side of IVD hernia location was $1441.2 \pm 13.7 \mathrm{~mm}^{2} / \mathrm{s}$, and for the roots on the intact side it was $1243.9 \pm 17.6 \mathrm{~mm}^{2} / \mathrm{s}$ $(p<0.001)$. The average MDC values for the distal regions of roots on the side of IVD degeneration and on the intact side were $1446.8 \pm 173.4$ and $1107.5 \pm 76.1 \mathrm{~mm}^{2} / \mathrm{s}$, respectively $(p<0.001)$ (Figure 2$)$.

To simplify evaluation of the state of the neural structures with DWI mapping and MDC calculation were introduced $\mathrm{R}$ coefficient. This coefficient is a correlation of MDC neural structure (DSG or spinal root) on the side of IVD hernia location to MDC of the neural structure on the intact side. $R$ coefficients for DSG and the proximal region of the spinal root on IVD hernia side were 1.16 and 1.32 , and on the intact side were $0.98 \quad(p<0.01)$ and $1.0 \quad(p<0.001)$, respectively.

The analysis of morphometric DSG parameters on IVD hernia side and the intact side showed reliable differences in the length values $15.3 \pm 2.2$ and $10.6 \pm 1.3 \mathrm{~mm}$, respectively $(p<0.01)$ and in the width values $-6.7 \pm 0.8$ and $5.8 \pm 0.6 \mathrm{~mm}$, respectively $(p<0.001)$.

To evaluate clinical-neurological symptoms in patients with a degenerative disease of lumbar IVD in 23 patients $(62.1 \%)$ we verified the signs of radiculoneuralgia, in 10 cases $(27.02 \%)$ - radiculoneuritis and in $4(10.8 \%)$ - the signs of radiculopathy [18]. The average values of pain intensity according to VAS and the quality of life according to ODI were $6.2 \pm 3.3 \mathrm{~cm}$ and $59.8 \pm 14.5 \%$. The analysis of correlation between the MDC values of DSG, spinal nerve roots and the clinical parameters 


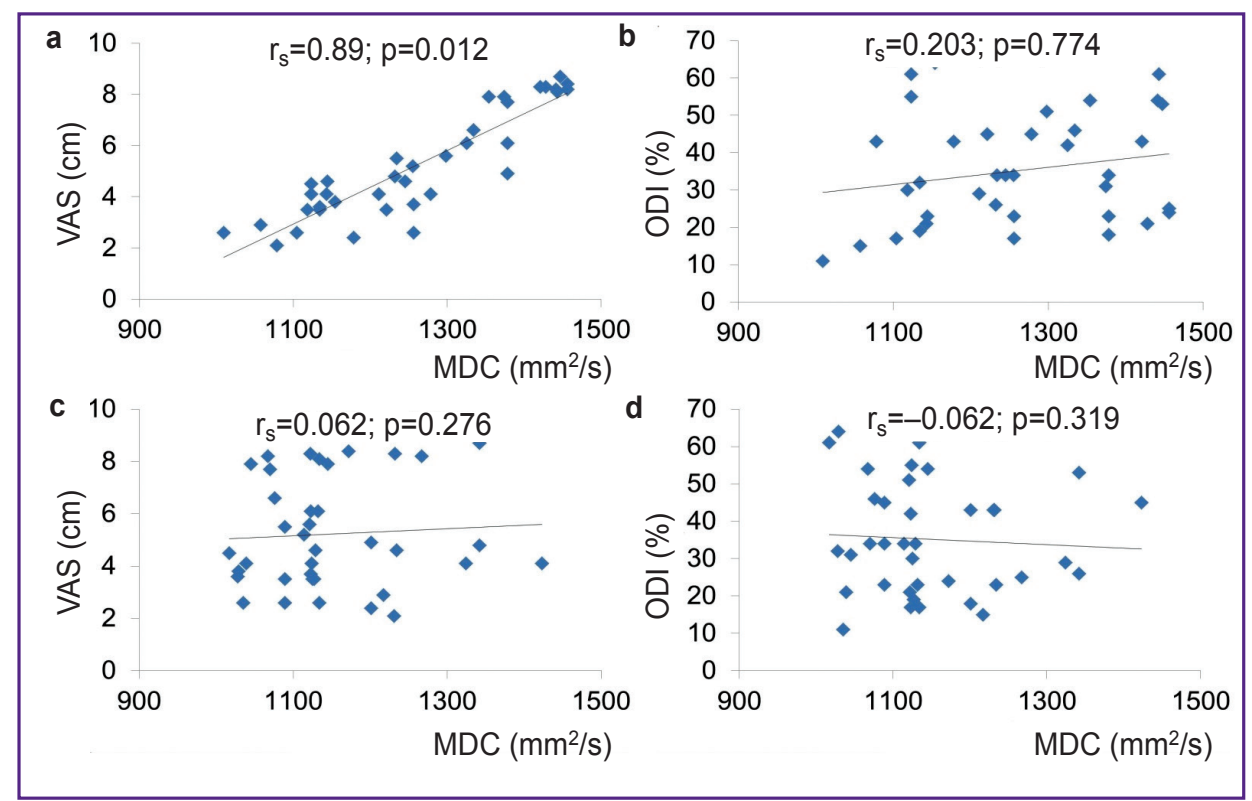

Figure 3. Analysis of correlation between MDC of DSG and the proximal region of the spinal nerve roots and the clinical parameters:

(a) between MDC of DSG and the degree of intensity according to VAS; (b) between MDC of DSG and the quality of patients' life according to ODI; (c) between MDC of the proximal region of the roots and the degree of intensity according to VAS; (d) between MDC of the proximal region of the roots and the patients' quality of life according to ODI

showed that between MDC of DSG and the pain intensity according to VAS there is statistically relevant direct correlation $\left(r_{s}=0.089 ; p=0.012\right)$ (Figure 3$)$.

\section{Discussion}

As previously reported, the main role in the development of nerve root pain syndrome in IVD hernias belongs to DSG. When neural structures are compressed with IVD hernias, two main pathophysiological processes occur - mechanical compression of the spinal nerve root itself and compression of vessels which are involved in feeding those roots [18].

Olmarker et al. in 1989 [19] showed that long-term compression of spinal nerve roots lead to their edema and demyelination. Morphological tests of the patients with significant foraminal stenosis confirm the presence of degenerative changes in spinal nerve roots [20]. As a rule, these degenerative changes include demyelination and the loss of axons. As Takata et al. [21] observed, multi-layer spiral CT-myelography showed that in lumbar IVD hernias there was significant edema of spinal nerve roots. Toyone et al. [22] stated that MRI investigation of the lumbosacral spine with intravenous contrasting allows the clearest visualization of the neural structures compressed with IVD hernia. Some authors suppose that this visualization enhancement is associated with partial damage of histochematic "blood-root" barrier [23]. Others [24] are of the opinion that improvement of visualization of the nerve roots compressed with
IVD during MRI investigation with contrast is caused by varicose branches of radicular veins which increase signal intensity in MRI images. In some works [25, 26] it is noted that intensification of the signal from spinal nerve roots after decompressing surgery resulted from microtrauma caused by the neurosurgeon. On the other hand, it has been shown [27] that MRI myelography can help verify edema of spinal nerve roots and the edema intensity reliably correlates with clinical neurological symptoms of lumbar IVD herniation.

Baliyan et al. [28] in their study showed that when peripheral nerves are damaged in the early period (up to 6 days) the data in DWI maps show limitation in diffusion degree of free water molecules. However, 1-4 weeks after the nerve damage the average MDC values increase considerably, and this fact reflects microstructural changes in the nervous tissue manifested by demyelination, edema and axonal damage. The study [29] also confirmed a significant increase in average $M D C$ values when a sciatic nerve was injured in frogs in the experiment.

The previous investigations studying the use of DW MRI with MDC calculations in diagnostics of various pathological states of the nervous system demonstrated high sensitivity and specificity of this method in diagnostics of multiple sclerosis, carpal tunnel syndrome and various demyelinating processes [13-15]. We could find the information about the use of DW MRI in diagnostics of compression of spinal nerve roots in degenerative IVD disease only in the following 
work [16]. But it should be mentioned that this study, unfortunately, has its own drawbacks. It considers an insignificant number of respondents with degeneration of lumbar IVD and healthy volunteers. The work does not consider clinical-neurological symptoms of patients with sciatica, which is an important aspect in diagnostics of compression of spinal nerve roots in patients with hernias of lumbar IVD. According to our findings, compressed with lumbar IVD hernias spinal nerve roots and DSG of the spinal cord have reliably high MDC values compared to intact nerve roots and DSG. It can be supposed that those high MDC values are caused by edema and myelination of the given neural structures. Upon the whole, the obtained results of our study mainly correlate with the findings obtained by Eguchi et al. [16].

This study also has some downsides which should be specified. Firstly, it has a retrospective character and involves a small number of patients which affected the results of statistical processing. Secondly, when we identified MDC values of DSG and spinal nerve roots we did not specify the regions of interest; it also had an impact on calculation of MDC values. Thirdly, our work did not consider the results of electroneuromyography the patients had undergone, but that investigation allows reliable evaluation of the spinal nerve roots. And finally the investigation did not consider morphological types of MDC hernias such as protrusions and extrusions.

\section{Conclusion}

The study shows effectiveness of using DW MRI with DWI mapping and MDC calculation in diagnostics of spinal nerve compression in patients with lumbar IVD herniation. There is a statistically relevant direct correlation between pain intensity and according to VAS and MDC values of DSG. The main specificity of compressed DSG and spinal nerve compression is high MDC values, which in all probability reflects microstructural changes of the latter in the form of edema, demyelination and axonal injury. We believe that DW MRI is a perspective method of non-invasive instrumental diagnostics of compressed nerve root syndromes in patients with an IVD disease.

Funding. The study was financially supported by the Innovation Promotion Fund (Project No.40838).

Conflict of interest. The authors declare no conflict of interest to be reported.

\section{References}

1. Mixter W.J., Barr J.S. Rupture of the intervertebral disc with involvement of the spinal canal. N Engl J Med 1934; 211: 210-215, https://doi.org/10.1056/nejm193408022110506.

2. Krames E.S. The dorsal root ganglion in chronic pain and as a target for neuromodulation: a review. Neuromodulation 2015; 18(1): 24-32, https://doi.org/10.1111/ ner.12247.

3. Forget P., Boyer T., Steyaert A., Masquelier E.,
Deumens R., Le Polain de Waroux B. Clinical evidence for dorsal root ganglion stimulation in the treatment of chronic neuropathic pain. A review. Acta Anaesthesiol Belg 2015; 66(2): 37-41.

4. Byvaltsev V.A., Stepanov I.A., Kalinin A.A., Shashkov K.V. Diffusion-weighted magnetic resonance tomography in the diagnosis of intervertebral disk degeneration. Biomedical Engineering 2016; 50(4): 253-256, https://doi.org/10.1007/s10527-016-9632-0.

5. Byval'tsev V.A., Stepanov I.A., Kalinin A.A., Belykh E.G. Diffusion-weighted magnetic resonance imaging in the diagnosis of intervertebral disc degeneration in the lumbosacral spine. Vestnik rentgenologii i radiologii 2016; 97(6): 357-364.

6. Byvaltsev V.A., Stepanov I.A., Kalinin A.A., Belykh E.G. Quantitative assessment of the degree of degenerative change in intervertebral disks using diffusion-weighted images. Biomedical Engineering 2017; 51(4): 275-279, https://doi. org/10.1007/s10527-017-9730-7.

7. Byvaltsev V.A., Kolesnikov S.I., Belykh E.G., Stepanov I.A., Kalinin A.A., Bardonova L.A., Sudakov N.P., Klimenkov I.V., Nikiforov S.B., Semenov A.V., Perfil'ev D.V., Bespyatykh I.V., Antipina S.L., Giers M., Prul M. Complex analysis of diffusion transport and microstructure of an intervertebral disk. Bull Exp Biol Med 2017; 164(2): 223-228, https://doi.org/10.1007/s10517-017-3963-z.

8. Byval'tsev V.A., Stepanov I.A., Semenov A.V., Perfil'ev D.V., Belykh E.G., Bardonova L.A., Nikiforov S.B., Sudakov N.P., Bespyatykh I.V., Antipina S.L. The possibilities for diagnostics of prescription of death coming based on the changes in the lumbar intervertebral disks (the comparison of the morphological, immunohistochemical and topographical findings). Sudebno-meditsinskaya ekspertiza 2017; 60(4): 4-8.

9. Belykh E., Kalinin A.A., Patel A.A., Miller E.J., Bohl M.A., Stepanov I.A., Bardonova L.A., Kerimbaev T., Asantsev A.O., Giers M.B., Preul M.C., Byvaltsev V.A. Apparent diffusion coefficient maps in the assessment of surgical patients with lumbar spine degeneration. PLoS One 2017; 12(8): e0183697, https://doi.org/10.1371/journal.pone.0183697.

10. Byvaltsev V.A., Stepanov I.A., Kalinin A.A., Belykh E.G. The use of apparent diffusion coefficient in diagnosis of lumbar intervertebral disk degeneration in patients with middle and old age by diffusion-weighted MRI. Uspekhi gerontologii 2018; 31(1): 103-109.

11. Ohgiya Y., Oka M., Hiwatashi A., Liu X., Kakimoto N., Westesson P.A., Sven E., Ekholm S. Diffusion tensor MR imaging of the cervical spinal cord in patients with multiple sclerosis. Eur Radiol 2007; 17(10): 2499-2504, https://doi. org/10.1007/s00330-007-0672-4.

12. Hiltunen J., Suortti T., Arvela S., Seppa M., Joensuu R., Hari R. Diffusion tensor imaging and tractography of distal peripheral nerves at 3 T. Clin Neurophysiol 2005; 116: 23152323, https://doi.org/10.1016/j.clinph.2005.05.014.

13. Martín Noguerol T., Barousse R., Socolovsky M., Luna A. Quantitative magnetic resonance (MR) neurography for evaluation of peripheral nerves and plexus injuries. Quant Imaging Med Surg 2017; 7(4): 398-421, https://doi. org/10.21037/qims.2017.08.01.

14. Yamashita T., Kwee T.C., Takahara T. Whole-body magnetic resonance neurography. N Engl J Med 2009; 361(5): 538-539, https://doi.org/10.1056/nejmc0902318.

15. Takahara T., Imai Y., Yamashita T., Yasuda S., Nasu S. Van Cauteren M. Diffusion weighted whole body imaging 
with background body signal suppression (DWIBS): technical improvement using free breathing, STIR and high resolution 3D display. Radiat Med 2004; 22(4): 275-282.

16. Eguchi Y., Ohtori S., Yamashita M., Yamauchi K., Suzuki M., Orita S., Kamoda H., Arai G., Ishikawa T., Miyagi M., Ochiai N., Kishida S., Inoue G., Masuda Y., Ochi S., Kikawa T., Toyone T., Takaso M., Aoki Y., Takahashi K. Diffusion-weighted magnetic resonance imaging of symptomatic nerve root of patients with lumbar disk herniation. Neuroradiology 2011; 53(9): 633-641, https://doi.org/10.1007/s00234-010-0801-7.

17. Williams J.R. The declaration of Helsinki and public health. Bull World Health Organ 2008; 86(8): 650-652, https:// doi.org/10.2471/blt.08.050955.

18. Blagodatskiy M.D., Meyerovich S.I. Diagnostika $i$ lechenie diskogennogo poyasnichno-kresttsovogo radikulita [Diagnosis and treatment of discogenic lumbosacral radiculitis]. Irkutsk: Izd-vo Irkutskogo un-ta; 1987; 271 p.

19. Olmarker K., Rydevik B., Holm S. Edema formation in spinal nerve roots induced by experimental, graded compression: an experimental study on the pig cauda equina with special reference to differences in effects between rapid and slow onset of compression. Spine 1989; 14(6): 569-573, https://doi.org/10.1097/00007632-198906000-00003.

20. Xue F., Wei Y., Chen Y., Wang Y., Gao L. A rat model for chronic spinal nerve root compression. Eur Spine J 2014; 23(2): 435-446, https://doi.org/10.1007/s00586-013-2990-3.

21. Takata K., Inoue S., Takahashi K., Ohtsuka Y. Swelling of the cauda equina in patients who have herniation of a lumbar disc. A possible pathogenesis of sciatica. $J$ Bone Joint Surg Am 1988; 70(3): 361-368, https://doi.org/10.2106/00004623$198870030-00007$.

22. Toyone T., Takahashi K., Kitahara H., Yamagata M., Murakami M., Moriya $\mathrm{H}$. Visualisation of symptomatic nerve roots. Prospective study of contrast-enhanced MRI in patients with lumbar disc herniation. J Bone Joint Surg Br 1993; 75(4): 529-533, https://doi.org/10.1302/0301-620x.75b4.8331104.

23. Germon T., Singleton W., Hobart J. Is NICE guidance for identifying lumbar nerve root compression misguided? Eur Spine J 2014; 23(S1): 20-24, https://doi.org/10.1007/s00586014-3233-y.

24. Lane J.I., Koeller K.K., Atkinson J.L. Contrast-enhanced radicular veins on MR of the lumbar spine in an asymptomatic study group. AJNR Am J Neuroradiol 1995; 16(2): 269-273.

25. Boden S.D., Davis D.O., Dina T.S., Parker C.P., O'Malley S., Sunner J.L., Wiesel S.W. Contrast-enhanced MR imaging performed after successful lumbar disk surgery: prospective study. Radiology 1992; 182(1): 59-64, https://doi. org/10.1148/radiology.182.1.1727310.

26. Park C.-K., Lee H.-J., Ryu K.-S. Comparison of root images between post-myelographic computed tomography and magnetic resonance imaging in patients with lumbar radiculopathy. Journal of Korean Neurosurgical Society 2017; 60(5): 540-549, https://doi.org/10.3340/jkns.2016.0809.008.

27. Al-Tameemi H.N., Al-Essawi S., Shukri M., Naji F.K. Using magnetic resonance myelography to improve interobserver agreement in the evaluation of lumbar spinal canal stenosis and root compression. Asian Spine J 2017; 11(2): 198-203, https://doi.org/10.4184/asj.2017.11.2.198.

28. Baliyan V., Das C.J., Sharma R., Gupta A.K. Diffusion weighted imaging: technique and applications. World J Radiol 2016; 8(9): 785-798, https://doi.org/10.4329/wjr.v8.i9.785.

29. Ding W.Q., Gu J.H., Yuan Y., Jin D.S. Stereoscopic display of the peripheral nerves at the elbow region based on MR diffusion tensor imaging with multiple post-processing methods. Iran J Radiol 2016; 13(1): e22144, https://doi. org/10.5812/iranjradiol.22144. 